\title{
Monitoring seasonal variations in seismic velocity and groundwater levels in Harvey, Western Australia using borehole ambient seismic noise interferometry
}

\author{
Leiyu He ${ }^{1,2}$, Erdinc Saygin ${ }^{2,3}$, David Lumley ${ }^{2,4}$, Chaoying Bai ${ }^{1}$ \\ ${ }^{1}$ Department of Geophysics, Chang'an University, Xi'an, China \\ ${ }^{2}$ Department of Physics, The University of Western Australia, Perth, Australia \\ ${ }^{3}$ Deep Earth Imaging, Future Science Platform, CSIRO, Perth, Australia \\ ${ }^{4}$ School of Natural Sciences and Mathematics, The University of Texas at Dallas, Dallas, USA
}

\section{Key Points:}

- We use ambient seismic noise recorded in a borehole to monitor changes of seismic velocity using interferometric analysis in Harvey.

- We find that the change in seismic velocity is seasonal and strongly correlated with changes in near-surface groundwater levels.

- Modeled elastic and poroelastic velocity changes are consistent with the observed seismic velocity changes.

Corresponding author: Leiyu He, leiyuhe@chd.edu.cn 


\begin{abstract}
In order to explore the relationships between environmental subsurface changes and seismic velocities, we use nearly four years (2015-2018) of continuous ambient seismic noise data recorded in a multi-level borehole sensor array to measure relative seismic velocity changes at the SW Hub $\mathrm{CO}_{2}$ Geosequestration Site in Harvey, Western Australia using seismic noise interferometry. We find a direct correlation between seismic velocity and seasonal groundwater changes, where seismic velocity changes follow groundwater level changes. Our rock and fluid physics modeling are highly consistent with the observations suggesting the seismic velocity changes are a direct result of groundwater table fluctuations.
\end{abstract}

\title{
Plain Language Summary
}

Groundwater resources are extremely important for society. In the context of global climate change, human activities have greatly changed the distribution and utilization potential of groundwater resources. Dynamic monitoring of groundwater level changes is of great significance for the rational use and protection of groundwater resources. By analyzing the ambient seismic noise recorded with geophones, we show that we can indirectly monitor the changes in groundwater level in Harvey, Western Australia. We find that the velocity change curve is highly correlated with the groundwater level change. Our analyses show that it is feasible to use ambient seismic noise data to monitor groundwater level changes.

\section{Introduction}

The surface layer of the earth supports life and has become known as the Critical Zone (Brantley et al., 2007). This area ranges from the top of the vegetation canopy down to the bottom of the aquifer (H. Lin, 2010). In order to meet society's increasing demand for food and water resources, the use of plant and soil will be expanded in the next few decades with the effect that the critical zone $(\mathrm{CZ})$ will be increasingly impacted by human activities, including land and groundwater use (D. d. Richter \& Mobley, 2009), so research on the $\mathrm{CZ}$ will be important to optimally manage the use of these resources. Based on this, the role of ambient seismic noise is increasingly important and gives us new approaches to study the physical properties of the CZ (Larose et al., 2015).

Ambient seismic noise has proven to be an extremely useful method and has been applied in many areas of seismology (Lecocq et al., 2014; Larose et al., 2015), where it has been used for subsurface imaging (Shapiro et al., 2005; F.-C. Lin et al., 2008; Poli et al., 2012; Saygin \& Kennett, 2012; Issa et al., 2017), and environmental monitoring (Mainsant et al., 2012; Minato et al., 2012; Froment et al., 2013).

Since seismic noise is continuous, ubiquitous, it gives the opportunity to study temporal changes of the subsurface over time (Nakata et al., 2019). Recently, many studies use ambient seismic noise to measure relative seismic velocity changes (dv/v), such as groundwater level changes (Sens-Schönfelder \& Wegler, 2006; Lecocq et al., 2017; Clements \& Denolle, 2018; Yang et al., 2018; Kim \& Lekic, 2019), temperature induced changes (T. Richter et al., 2014; Mao et al., 2019), earth tide variations (Hillers et al., 2015; Mao et al., 2019), subsurface changes from volcanic activity (Brenguier, Shapiro, et al., 2008; Bennington et al., 2018; De Plaen et al., 2019; Yates et al., 2019), stress variations caused by post-seismic relaxation (Brenguier, Campillo, et al., 2008; Hobiger et al., 2012; Obermann et al., 2014; Hillers et al., 2019), and other applications.

The SW Hub Project is located in the South Perth Basin of Western Australia, approximately $110 \mathrm{~km}$ south of the state capital Perth. The project site represents a major carbon capture and storage (CCS) research effort, intending to store industrial $\mathrm{CO}_{2}$ 
from coal-fired power plants, mineral processing facilities and other sources, in order to help meet Australia's national $\mathrm{CO}_{2}$ emission reduction goals (Stalker et al., 2013). As a part of the project, in order to characterize natural environmental seismicity prior to any $\mathrm{CO}_{2}$ injection, an eight-element $44 \mathrm{~m}$ deep seismic borehole was deployed and operated continuously with three-component sensors between 2015 and 2018 (Lumley et al., 2015).

The primary goal of this study is to explore the cause of seasonal seismic velocity changes (dv/v) observed at the SW Hub $\mathrm{CO}_{2}$ Geosequestration Site borehole, by integrating continuous seismic noise recordings using interferometric analysis. The borehole array is approximately $17 \mathrm{~km}$ east of the Indian Ocean coast (Figure 1a), where highly energetic ocean seismic noise was recorded during the operation of the borehole. In our analyses, we integrate other environmental datasets such as groundwater, tidal, rainfall and temperature data to investigate whether there is an apparent correlation between these environmental phenomena and the observed seismic velocity changes.

\section{Data and Methods}

\subsection{Data}

The seismic data were recorded continuously at the borehole array between August 2015 and April 2018 at a sampling rate of $1 \mathrm{kHz}$. The borehole comprises eight levels of three-component $15 \mathrm{~Hz}$ geophones of broad sensitivity range; with a vertical element spacing of $6 \mathrm{~m}$ (Figure 1b) where the deepest sensor element is located at $44 \mathrm{~m}$. During the nearly three year operation of the borehole, there was only a limited amount of downtime of approximately five months in total.

\subsection{Noise Cross-correlations \& Measuring Seismic Velocity Changes}

The cross-correlation operation can turn "noise" into a useful signal by providing an estimate of Green's functions between seismic stations (Bensen et al., 2007). Most of the noise tomography results and time-lapse analyses are based on cross-correlations retrieval (Nakata et al., 2019). Since ambient seismic noise is recorded continuously, these cross-correlations can also be used to estimate the relative variations in velocities (Clarke et al., 2011).

We calculate three kinds of cross-correlation functions using all three components of the geophones: "vertical-vertical", "north-north", and "east-east" and other cross-component correlations. Daily cross-correlations are calculated using a deconvolution technique (Helmberger \& Wiggins, 1971), where the raw data is detrended (remove mean and trend) and a one hour correlation window with no overlap is used in the computations. For the end of each day, the resulting cross-correlations from each sensor pair are stacked to create a daily stacked cross-correlation. The whole suite of cross-correlation is shown in the Supporting Information (Figure S1).

After calculating the cross-correlations from the inter-elements of the borehole for each day, we measure the relative velocity change by comparing each day's cross-correlation with a reference cross-correlation created from the average of all cross-correlations using the Moving Window Cross-Spectrum (MWCS) method of Clarke et al. (2011); Lecocq et al. (2014). The MWCS technique has the advantage of operating in the frequency domain, where the bandwidth of a coherent signal in the correlation function can be clearly defined (Clarke et al., 2011). This method calculates relative velocity changes by comparing the 'reference' waveform with the 'observed' waveform (Clarke et al., 2011).

In the calculations, we use both acausal and causal data time windows spanning from -4 to $4 \mathrm{~s}$ for the analysis windows for cross-correlations. We also test the influence of user-selected parameters in the estimation of $\mathrm{dv} / \mathrm{v}$ by trying different windows and 
step sizes. In the end, we use $0.2 \mathrm{~s}$ as the size of the moving window, and $0.04 \mathrm{~s}$ for the step size (20\% of the window size), which yields robust and consistent measurements. Our test results show that velocity perturbation estimates are generally not sensitive to input parameters, i.e., window and step sizes (see Figure S5-S7), suggesting the robustness of our measurements. In order to ensure the accuracy of the calculations, and to eliminate the influence of noisy data segments, we only retain data with a coherency (mean coherence for each window) greater than 0.75 when calculating $\mathrm{dv} / \mathrm{v}$. The $\mathrm{dv} / \mathrm{v}$ curve is shown in Figure 2a-c and Figure 3a.

Since each sensor has three components, we calculated $84(3 \times 28)$ cross-correlation functions for all 28 possible combinations for each of the sensor components. For each cross-correlation function, we calculated the corresponding velocity change compared to the overall average. In Figures $2 \mathrm{a}-\mathrm{c}$, we plot the relative velocity changes measured at 1-5 Hz for three different components (Z-Z, N-N, E-E), where each colored curve is the velocity curve for a different cross-correlation and the thick black line is the average curve for all combinations (colored curve) of sensor pairs.

Previous studies (Obermann et al., 2013) have shown that the seismic coda wave is composed of surface waves and scattered body waves, the surface wave dominates the early times and scattered body waves dominate the later times. In our analyses, we use a time window from $-4 \mathrm{~s}$ to $4 \mathrm{~s}$ which is mostly dominated by deterministic surface waves with typical moveouts around $100 \mathrm{~m} / \mathrm{s}$ (Figure S11) and also its coda. In this window, it is expected to see the contribution of coda waves of both surface and body waves types as well as the deterministic surface waves as demonstrated by previous studies (Obermann et al., 2013, 2014). For the surface waves part, we calculate the sensitivity of Rayleigh waves between 1 and $25 \mathrm{~Hz}$ (Herrmann, 1987) for a Vs velocity model derived from Lumley et al. (2015) (See supporting information Figure S10). In this frequency range, phase velocities of Rayleigh waves are most sensitive to velocity structure in the top $800 \mathrm{~m}$. For comparison, we also calculated the relative velocity changes of other frequency ranges (See Figure S2 - S4 in Supporting information), it can be seen that the amplitude of the relative velocity changes at $1-5 \mathrm{~Hz}$ is the largest, followed by $5-10 \mathrm{~Hz}$ and $10-25 \mathrm{~Hz}$ as the smallest. We also find that most of the energy is concentrated in $1-10 \mathrm{~Hz}$ by applying a time-frequency analysis (See Figure S12 - S20), which possibly explains the observed dominant amplitudes of the velocity changes between 1 and $5 \mathrm{~Hz}$.

From Figures 2a-c, we observe that the dv/v curve has obvious seasonal and periodic variations ( $\pm 0.5 \%$ on average) and its wavelength of change is about one year. It reaches a negative maximum around September of each year and a positive maximum around April of the following year. These phenomena can be observed across all of the channel combinations of Z-Z, N-N, and E-E and other cross-components combinations (See Figure 3a).

Figure 2d shows the Reduced Standing Water Level (RSWL: the elevation of the water level is calculated by subtracting the depth to water from a reference elevation) after normalization. Since there is no groundwater data available directly at the shallow seismic borehole, we select data from 11 nearby groundwater boreholes from Australian Groundwater Explorer that cover the majority of the recording duration from 2015 to 2018. Given the different baselines of groundwater changes in each groundwater borehole, we normalize the data to identify the trends better. See Figure S8 for the absolute groundwater data in the supporting information). The tidal variations, precipitation and the ambient air temperature are given in Figures 2d-e. We also see that these environmental data exhibit a strong seasonal, but a time-lagged, variation.

The general trend of groundwater variations in all of the 11 nearby wells is highly consistent (Figure 2d) and shows a high level of correlation with dv/v (Figure 2a-d). Previous studies have explored the relationship between seismic velocity and groundwater level changes. One common observation found was that as groundwater levels rise, the 
$\mathrm{dv} / \mathrm{v}$ will decrease gradually, producing a clear negative correlation between the two parameters (Gassenmeier et al., 2014; Sens-Schönfelder \& Wegler, 2006; Clements \& Denolle, 2018). In October of 2015, the groundwater amplitude increases to a maximum, the result of increased precipitation during the rainy season, and in April of 2016, it drops to the minimum because of the lack of precipitation (2015.09 - 2016.04) (Commander, 2013). This process can be explained by Darcy's Law if the groundwater variations occur through a stationary aquifer, the groundwater level changes in the aquifer will cause the velocity change (Sens-Schönfelder \& Wegler, 2011). The patterns of change in other years are similar. The periodicity of groundwater variation is also about one year, equal to the wavelength of the change in $\mathrm{dv} / \mathrm{v}$. The correlation coefficient between mean $\mathrm{dv} / \mathrm{v}$ and normalised mean RSWL is 0.928 , the delay time between these two factors is almost 0 day, indicating a significant likelihood that the change in $\mathrm{dv} / \mathrm{v}$ is caused by groundwater level changes. However, Kim and Lekic (2019) have found that the relationship between these two parameters can be positively correlated. The primary reason behind the positive correlation is that auto-correlation method was used to calculate $\mathrm{dv} / \mathrm{v}$ rather than cross-correlation in their study, they modeled the velocity change and found the $\mathrm{dv} / \mathrm{v}$ is primarily sensitive the $\mathrm{P}$ wave velocity change.

Large earthquakes can also cause changes in the velocity of the subsurface (Hobiger et al., 2012; Minato et al., 2012). However, this change rate is more instantaneous rather than seasonal periodicity, and we did not find evidence of earthquake activity with $\mathrm{M}_{\mathrm{w}}$ magnitude greater than 4.0, within $50 \mathrm{~km}$ of Harvey, during the analyses period. The variation of tide also exhibits an expected natural seasonal pattern (See Figure 2e). We calculate the correlation coefficient between mean $\mathrm{dv} / \mathrm{v}$ and tide as 0.127 , and the delay time is about 86 days. Mao et al. (2019) estimated the order of seismic velocity variations induced by the tide to be approximately around $0.01 \%$, which is much smaller than the relative velocity variations that we observed. Consequently, we suggest that tidal variations are unlikely to be the primary cause of our observed seismic velocity changes.

The seismic velocities we observe do not show obvious correspondence with the temperature data unlike that observed by T. Richter et al. (2014). They reported a strong correlation between temperature and induced seasonal velocity changes. They found that if the velocity change is caused by temperature variations, a significant velocity change would have been observed within one day (T. Richter et al., 2014). We did not observe this phenomenon as shown in the diurnal plot (See Figure S9). The temperature-induced velocity change may be too small (less than $0.1 \%$ ) and not easily observed (Yang et al., 2018; T. Richter et al., 2014; Clements \& Denolle, 2018; Tsai, 2011). One possible reason is that our geophones are located in a borehole, thus being at depth they are less affected by surface heat fluctuations (T. Richter et al., 2014). We also calculate delay time between temperature and observed $\mathrm{dv} / \mathrm{v}$ as around 40 days, and the correlation coefficient between $\mathrm{dv} / \mathrm{v}$ and temperature is 0.400 , which is much smaller than the $\mathrm{dv} / \mathrm{v}$ and groundwater correlation. Interestingly, it can be seen from Figures S9 a-c that the noise fluctuations between 00:00-10:00 UTC (8:00-18:00 local time) are significantly higher than at other times, which is likely caused by the result of an increase in human and farm animal (cattle) activity during day time near the borehole.

\section{Modelling Seismic Velocity Changes}

In order to quantitatively evaluate the velocity change caused by groundwater, we use Tsai's model (Tsai, 2011) to calculate the velocity changes caused by groundwater and the velocity changes caused by temperature change. We use the rock physics parameter (bold) derived from the lab measurements of Lumley et al. (2015) given in Table $1-3$. 
Table 1. Thermoelastic modeling parameters. $m$ is the Murnaghan constant, $\mu$ is the shear modulus, $v$ is Poisson's ratio, $k$ is the horizontal wavenumber, $\omega$ is the frequency of annual variation, $\kappa$ is thermal diffusivity, $\Delta t$ is the delay between temperature variations and the observed $\mathrm{dv} / \mathrm{v}$ curve.

\begin{tabular}{lcccccc}
\hline$\frac{m}{\mu}$ & $\boldsymbol{v}$ & $\alpha_{t h}$ & $k$ & $\kappa$ & $\omega$ & $\Delta t$ \\
\hline-10000 & 0.2 & $10^{-5}{ }^{\circ} \mathrm{C}^{-1}$ & $2 \pi /(20 \mathrm{~km})$ & $10^{-6} \mathrm{~m}^{2} / \mathrm{s}$ & $2 \times 10^{-7} \mathrm{~s}^{-1}$ & $\approx 40$ days
\end{tabular}

Table 2. Direct elastic modeling parameters. $\phi$ is porosity, $P_{0}$ is pore pressure, $E$ is Young's modulus. Other parameters are the same as Table 1.

\begin{tabular}{lccccc}
\hline$\frac{m}{\mu}$ & $\boldsymbol{v}$ & $k$ & $\boldsymbol{\phi}$ & $\boldsymbol{P}_{\mathbf{0}}$ & $\boldsymbol{E}$ \\
\hline-10000 & 0.2 & $2 \pi /(20 \mathrm{~km})$ & 0.25 & $4.3 \times 10^{4} \mathrm{~Pa}$ & $1.6 \times 10^{10} \mathrm{~Pa}$ \\
\hline
\end{tabular}

Table 3. Poroelastic modeling parameters. $\alpha$ is the Biot-Willis coefficient, $\kappa_{h y}$ is hydraulic diffusivity. $\Delta t_{\text {poro }}$ is the delay between poroelastic effect and the groundwater level variations. Other parameters are the same as Table 2.

\begin{tabular}{lcccccccc}
\hline$\frac{m}{\mu}$ & $\boldsymbol{v}$ & $k$ & $\boldsymbol{\alpha}$ & $\boldsymbol{\phi}$ & $\boldsymbol{P}_{\mathbf{0}}$ & $\boldsymbol{E}$ & $\boldsymbol{\kappa}_{\boldsymbol{h y}}$ & $\boldsymbol{\Delta}$ \\
\hline-10000 & 0.2 & $2 \pi /(20 \mathrm{~km})$ & 0.25 & 0.25 & $4.3 \times 10^{4} \mathrm{~Pa} \boldsymbol{o}$ & $1.6 \times 10^{10} \mathrm{~Pa}$ & $2.5 \mathrm{~m}^{2} / \mathrm{s}$ & 11 days \\
\hline
\end{tabular}

\subsection{Temperature induced velocity changes}

We use the following model of Tsai (2011) to calculate the dv/v induced by temperature changes. The velocity changes due to the temperature can be approximated by:

$$
d v / v \approx \frac{m}{\mu} A(t) e^{-k y} \sin (k x)(1-2 v)
$$

where strain caused by temperature is $A(t)$ is given by:

$$
A(t)=\frac{1+v}{1-v} k \alpha_{t h} T_{0} \sqrt{\frac{\kappa}{\omega}} e^{\pi / 4-\omega \Delta t} \cos [\omega(t-\Delta t)]
$$

$m$ is the Murnaghan constant, $\mu$ is the shear modulus, $x$ is the horizontal position, $y$ is the depth, $t$ is time, $v$ is Poisson's ratio, $k$ is the horizontal wave number, $\omega$ is the frequency of annual variation, $\kappa$ is thermal diffusivity, $T_{0}$ is half of the peak to peak amplitude of the temperature variation, $\Delta t$ is the delay between temperature variations and the observed $\mathrm{dv} / \mathrm{v}$ curve. The parameters are given in Table 1 , where $v$ is from Lumley et al. (2015), other parameters are from Tsai (2011); Clements and Denolle (2018).

By comparing the modelling results (See Figure 3d), we find that the velocity effect of temperature is minimal (less than $0.04 \%$ ), which is not sufficient to generate observed velocity change. We conclude that temperature can not be a significant cause of the observed relative velocity changes at the Harvey seismic borehole.

\subsection{Groundwater induced velocity changes}

In Tsai (2011), two mechanisms are proposed to describe the seismic velocity changes caused by groundwater, 1) Direct elastic model, 2) Poroelastic model. 
For the direct elastic model, by a simple substitution of $A(t)$ to $A_{e}(t)$, where $A_{e}(t)$ is:

$$
A_{e}(t)=\frac{(1+v) \phi P_{0}}{E}
$$

where $\phi$ is porosity, $P_{0}$ is pore pressure, $E$ is Young's modulus. See Table 2 for other parameters. If the water variation is $4.3 \mathrm{~m}$, the $P_{0}=4.3 \times 10^{4} \mathrm{~Pa}$, the modeled and observed data match is reasonable (See real groundwater level changes in Figure S8). Other parameters are the same as the thermoelastic model.

Substituting these into Equation 1 then we can get the velocity caused by direct elastic effect (See Figure 3c).

For the poroelastic model, the calculation is similar to thermoelastic model, because (double-headed arrow representing logical equivalence),

$$
\frac{\alpha_{t h} E T}{1-2 v} \leftrightarrow \alpha P
$$

$$
\kappa \leftrightarrow \kappa_{h y},
$$

where $\alpha$ is the Biot-Willis coefficient, $\kappa_{h y}$ is hydraulic diffusivity, by substituting these to Equation 2, we can get $A_{\text {poro }}(t)$, then we can get $\mathrm{dv} / \mathrm{v}$ caused by poroelastic effect (See Figure 3c).

The modeled $\mathrm{dv} / \mathrm{v}$ (Figure 3c) shows a similar pattern in both direct elastic and poroelastic model, the calculated amplitude is basically consistent with the observed. But it is not completely consistent with the observed curve, because we use a simple cosine function to model the annual groundwater variations. The magnitude of the velocity change for the two models is directly related to the magnitude of the corresponding strain. The amplitude of $A_{\text {poro }}(t)$ is influenced by wavenumber $k$, therefore, decreasing $k$ results in a smaller velocity change but does not affect the direct elastic model (Tsai, 2011). This suggests that the direct elastic effect is most likely the cause of the observed seismic velocity change. However, these three calculations are just a reference, because not all parameters have been measured by lab experiments (e.g., $\frac{m}{\mu}$ ). More rock physics experiments using rocks/soil from the Harvey site would be required to make the calculation results more realistic.

\section{Conclusions}

In this study, we use continuous seismic borehole data to calculate seismic velocity changes at the SW Hub site in Harvey, Western Australia. We found that the measured velocity changes are similar at different frequencies with different amplitudes. In order to describe the observed relative seismic velocity changes, we study four different environmental datasets collected in the vicinity of the seismic borehole. We rule out the influence of temperature and tide on seismic velocity changes, since the observed changes at SW Hub are significantly larger than, and out of phase with, these effects. The change of groundwater level has a strong correlation (93\%) with the dv/v curve, where the delay time between groundwater fluctuations and observed velocity changes is very small. We use two different models of Tsai (2011) to quantify the seismic velocity changes with respect to the groundwater changes. Both the direct elastic and poroelastic models yield very similar amplitudes of $\mathrm{dv} / \mathrm{v}$. We conclude that the observed seismic velocity changes are most likely caused by the changes in groundwater levels at the SW Hub Borehole. 
Our research further shows that it is feasible to detect and monitor changes in groundwater level with passive seismic ambient noise data, which is useful for future studies of groundwater resources and the critical zone.

\section{Acknowledgments}

Leiyu He thanks CSC (China Scholarship Council) for funding. ObsPy, MsNoise packages were used in the processing of the seismic data. We thank the Department of Transport of Australia for the tidal data. The link is https://s3-ap-southeast-2.amazonaws .com/transport.wa/Tide_Packet/TideStations.kml. We also thank the Bureau of Meteorology of Australia for providing us rainfall, temperature and groundwater data http:// www. bom.gov.au/water/groundwater/explorer/map.shtml. Readers can access crosscorrelation functions data from https://doi.org/10.6084/m9.figshare.12366074.v1. We thank Yunfeng Chen and Caroline Johnson for reviewing an earlier version of the manuscript. The authors wish to acknowledge financial assistance provided through Australian National Low Emissions Coal Research and Development (ANLEC R\&D). ANLEC R\&D is supported by Australian Coal Association Low Emissions Technology Limited and the Australian Government through the Clean Energy Initiative.

\section{References}

Bennington, N., Haney, M., Thurber, C., \& Zeng, X. (2018). Inferring magma dynamics at veniaminof volcano via application of ambient noise. Geophysical Research Letters, 45(21), 11-650.

Bensen, G., Ritzwoller, M., Barmin, M., Levshin, A., Lin, F., Moschetti, M., ... Yang, Y. (2007). Processing seismic ambient noise data to obtain reliable broad-band surface wave dispersion measurements. Geophysical Journal International, 169(3), 1239-1260.

Brantley, S. L., Goldhaber, M. B., \& Ragnarsdottir, K. V. (2007). Crossing disciplines and scales to understand the critical zone. Elements, 3(5), 307-314.

Brenguier, F., Campillo, M., Hadziioannou, C., Shapiro, N., Nadeau, R. M., \& Larose, E. (2008). Postseismic relaxation along the san andreas fault at parkfield from continuous seismological observations. science, 321(5895), $1478-1481$.

Brenguier, F., Shapiro, N. M., Campillo, M., Ferrazzini, V., Duputel, Z., Coutant, O., \& Nercessian, A. (2008). Towards forecasting volcanic eruptions using seismic noise. Nature Geoscience, 1(2), 126.

Clarke, D., Zaccarelli, L., Shapiro, N., \& Brenguier, F. (2011). Assessment of resolution and accuracy of the moving window cross spectral technique for monitoring crustal temporal variations using ambient seismic noise. Geophysical Journal International, 186(2), 867-882.

Clements, T., \& Denolle, M. A. (2018). Tracking groundwater levels using the ambient seismic field. Geophysical Research Letters, 45(13), 6459-6465.

Commander, D. P. (2013). Groundwater resources of the lesueur carbon storage project area (sw hub). Department of Mines and Petroleum.

De Plaen, R. S., Cannata, A., Cannavo, F., Caudron, C., Lecocq, T., \& Francis, O. (2019). Temporal changes of seismic velocity caused by volcanic activity at mt. etna revealed by the autocorrelation of ambient seismic noise. Frontiers in Earth Science, 6, 251.

Froment, B., Campillo, M., Chen, J., \& Liu, Q. (2013). Deformation at depth associated with the 12 may 2008 mw 7.9 wenchuan earthquake from seismic ambient noise monitoring. Geophysical Research Letters, 40(1), 78-82.

Gassenmeier, M., Sens-Schönfelder, C., Delatre, M., \& Korn, M. (2014). Monitoring of environmental influences on seismic velocity at the geological storage site for co2 in ketzin (germany) with ambient seismic noise.

Geophysical Journal 
International, 200(1), 524-533.

Helmberger, D., \& Wiggins, R. A. (1971). Upper mantle structure of midwestern united states. Journal of Geophysical Research, 76(14), 3229-3245.

Herrmann, R. B. (1987). Computer programs in seismology. University.

Hillers, G., Campillo, M., Brenguier, F., Moreau, L., Agnew, D., \& Ben-Zion, Y. (2019). Seismic velocity change patterns along the san jacinto fault zone following the $2010 \mathrm{~m} 7.2$ el mayor-cucapah and m 5.4 collins valley earthquakes. Journal of Geophysical Research: Solid Earth, 124(7), 7171-7192.

Hillers, G., Retailleau, L., Campillo, M., Inbal, A., Ampuero, J.-P., \& Nishimura, T. (2015). In situ observations of velocity changes in response to tidal deformation from analysis of the high-frequency ambient wavefield. Journal of Geophysical Research: Solid Earth, 120(1), 210-225.

Hobiger, M., Wegler, U., Shiomi, K., \& Nakahara, H. (2012). Coseismic and postseismic elastic wave velocity variations caused by the 2008 iwate-miyagi nairiku earthquake, japan. Journal of Geophysical Research: Solid Earth, 117(B9).

Issa, N. A., Lumley, D., \& Pevzner, R. (2017). Passive seismic imaging at reservoir depths using ambient seismic noise recorded at the otway co2 geological storage research facility. Geophysical Journal International, $209(3)$, 1622-1628.

Kim, D., \& Lekic, V. (2019). Groundwater variations from autocorrelation and receiver functions. Geophysical Research Letters.

Larose, E., Carrière, S., Voisin, C., Bottelin, P., Baillet, L., Guéguen, P., ... others (2015). Environmental seismology: What can we learn on earth surface processes with ambient noise? Journal of Applied Geophysics, 116, 62-74.

Lecocq, T., Caudron, C., \& Brenguier, F. (2014). Msnoise, a python package for monitoring seismic velocity changes using ambient seismic noise. Seismological Research Letters, 85(3), 715-726.

Lecocq, T., Longuevergne, L., Pedersen, H. A., Brenguier, F., \& Stammler, K.

(2017). Monitoring ground water storage at mesoscale using seismic noise: 30 years of continuous observation and thermo-elastic and hydrological modeling. Scientific reports, 7(1), 14241.

Lin, F.-C., Moschetti, M. P., \& Ritzwoller, M. H. (2008). Surface wave tomography of the western united states from ambient seismic noise: Rayleigh and love wave phase velocity maps. Geophysical Journal International, 173(1), $281-298$

Lin, H. (2010). Earth's critical zone and hydropedology: concepts, characteristics, and advances. Hydrology and Earth System Sciences, 14(1), 25.

Lumley, D., King, A., Pevzner, R., Bona, A., Dautriat, J., Esteban, L., .. Urosevic, M. (2015). Feasibility and Design for Passive Seismic Monitoring at the $S W$ Hub CO2 Geosequestration Site: Australian National Low Emissions Council (ANLEC) RED Project Number7-0212-0203. University of Western Australia, Australia.

Mainsant, G., Larose, E., Brönnimann, C., Jongmans, D., Michoud, C., \& Jaboyedoff, M. (2012). Ambient seismic noise monitoring of a clay landslide: Toward failure prediction. Journal of Geophysical Research: Earth Surface, 117(F1).

Mao, S., Campillo, M., van der Hilst, R. D., Brenguier, F., Stehly, L., \& Hillers, G. (2019). High temporal resolution monitoring of small variations in crustal strain by dense seismic arrays. Geophysical Research Letters, 46(1), 128-137.

Minato, S., Tsuji, T., Ohmi, S., \& Matsuoka, T. (2012). Monitoring seismic velocity change caused by the 2011 tohoku-oki earthquake using ambient noise records. Geophysical Research Letters, 39(9).

Nakata, N., Gualtieri, L., \& Fichtner, A. (2019). Seismic ambient noise. Cambridge University Press.

Obermann, A., Froment, B., Campillo, M., Larose, E., Planes, T., Valette, B., ... Liu, Q. (2014). Seismic noise correlations to image structural and mechanical changes associated with the mw 7.92008 wenchuan earthquake.

Journal of 
Geophysical Research: Solid Earth, 119(4), 3155-3168.

Obermann, A., Planes, T., Larose, E., Sens-Schönfelder, C., \& Campillo, M. (2013). Depth sensitivity of seismic coda waves to velocity perturbations in an elastic heterogeneous medium. Geophysical Journal International, 194(1), 372-382.

Poli, P., Campillo, M., Pedersen, H., Group, L. W., et al. (2012). Body-wave imaging of earth's mantle discontinuities from ambient seismic noise. Science, 338(6110), 1063-1065.

Richter, D. d., \& Mobley, M. L. (2009). Monitoring earth's critical zone. Science, $326(5956), 1067-1068$.

Richter, T., Sens-Schönfelder, C., Kind, R., \& Asch, G. (2014). Comprehensive observation and modeling of earthquake and temperature-related seismic velocity changes in northern chile with passive image interferometry. Journal of Geophysical Research: Solid Earth, 119(6), 4747-4765.

Saygin, E., \& Kennett, B. (2012). Crustal structure of australia from ambient seismic noise tomography. Journal of Geophysical Research: Solid Earth, $117(\mathrm{~B} 1)$.

Sens-Schönfelder, C., \& Wegler, U. (2006). Passive image interferometry and seasonal variations of seismic velocities at merapi volcano, indonesia. Geophysical research letters, 33(21).

Sens-Schönfelder, C., \& Wegler, U. (2011). Passive image interferometry for monitoring crustal changes with ambient seismic noise. Comptes Rendus Geoscience, 343(8-9), 639-651.

Shapiro, N. M., Campillo, M., Stehly, L., \& Ritzwoller, M. H. (2005). Highresolution surface-wave tomography from ambient seismic noise. Science, 307 (5715), 1615-1618.

Stalker, L., Varma, S., Van Gent, D., Haworth, J., \& Sharma, S. (2013). South west hub: a carbon capture and storage project. Australian Journal of Earth Sciences, $60(1), 45-58$.

Tsai, V. C. (2011). A model for seasonal changes in gps positions and seismic wave speeds due to thermoelastic and hydrologic variations. Journal of Geophysical Research: Solid Earth, 116(B4).

Yang, W., Wang, B., Yuan, S., \& Ge, H. (2018). Temporal variation of seismic-wave velocity associated with groundwater level observed by a downhole airgun near the xiaojiang fault zone. Seismological Research Letters, 89(3), 1014-1022.

Yates, A., Savage, M., Jolly, A., Caudron, C., \& Hamling, I. (2019). Volcanic, coseismic, and seasonal changes detected at white island (whakaari) volcano, new zealand, using seismic ambient noise. Geophysical Research Letters, $46(1)$, 99-108. 


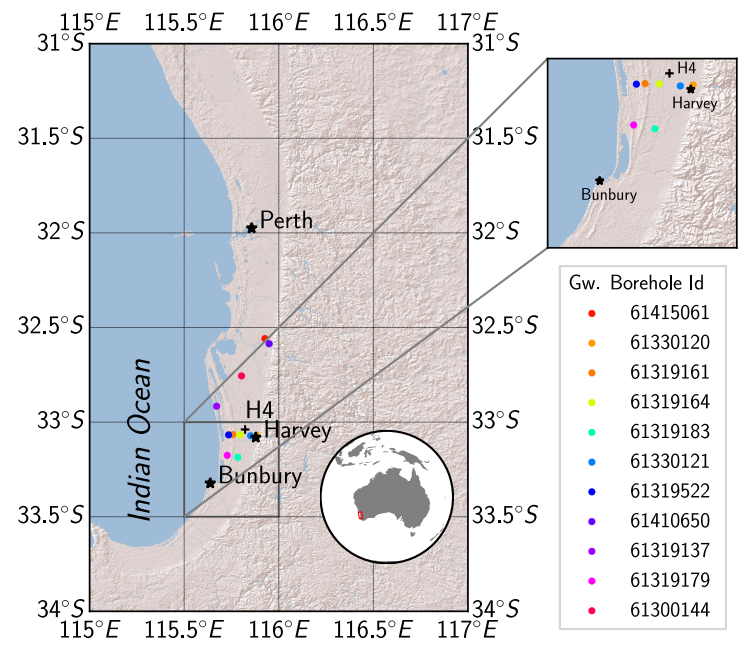

a)

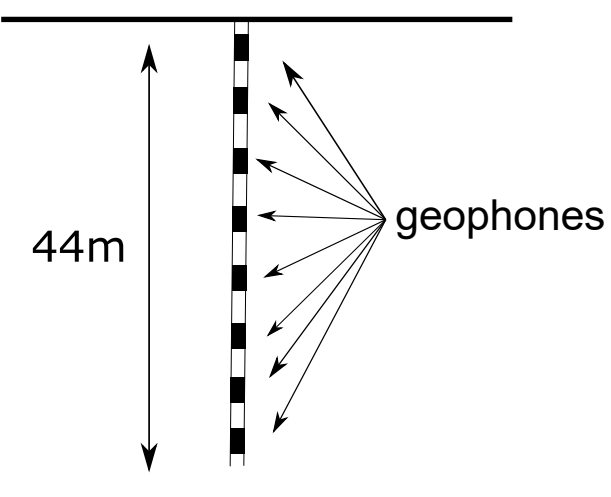

b)

Figure 1. a) The map shows the location of the H4 seismic borehole well (black cross) and groundwater boreholes (circles). The location of the nearby cities are shown with stars, and the red rectangle in the inset map shows the location of the study area. b) The schematic of the borehole array. 3C geophones (black rectangles) are positioned at depths: 2, 8, 14, 20, 26, 32, 38 and $44 \mathrm{~m}$ (Lumley et al., 2015).
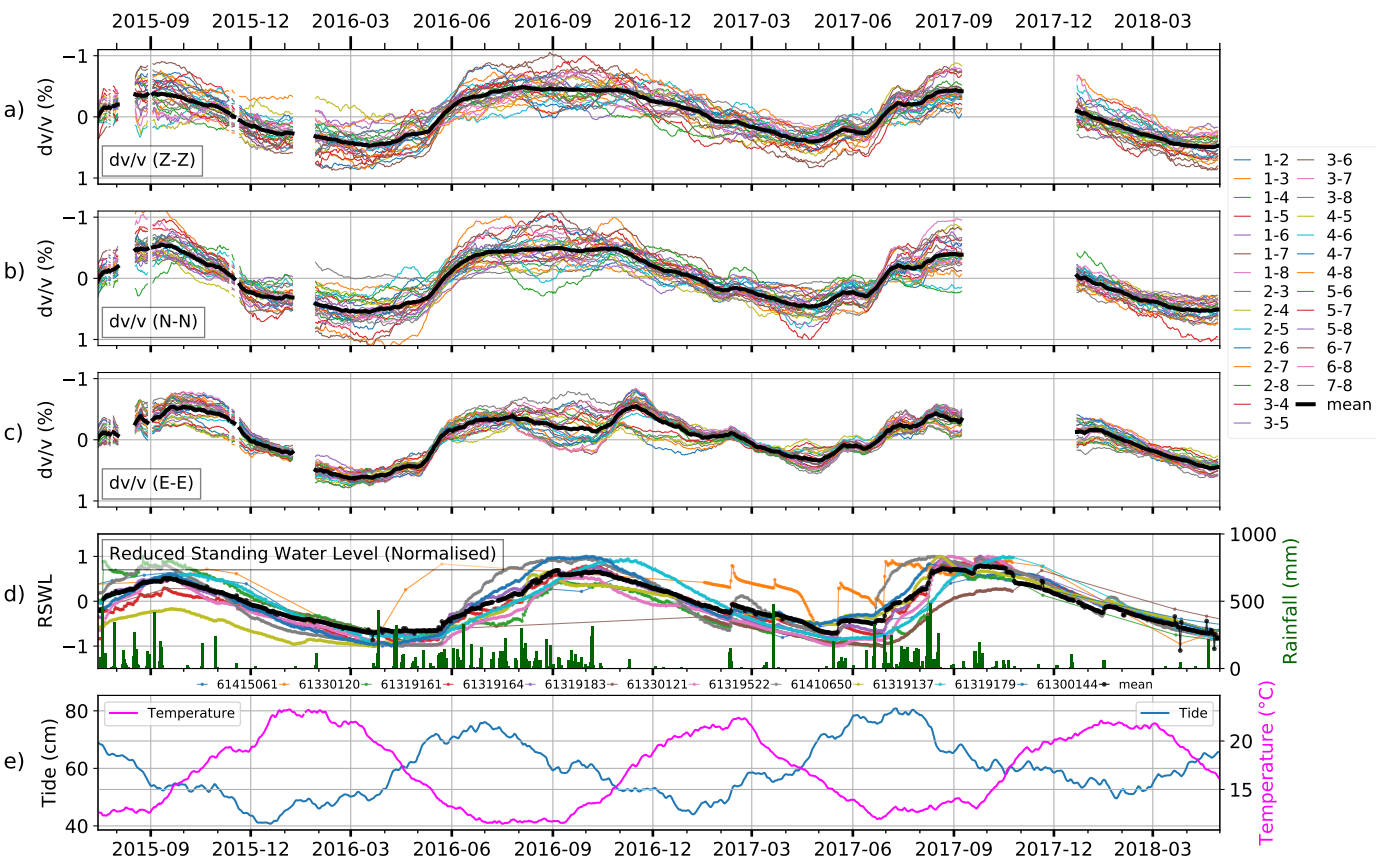

Figure 2. a) Relative velocity change as a function of time for Z-Z (1-5 Hz), the thick black line is the result of averaging all 28 curves. b) Same as $2 \mathrm{a}$, but for N-N. c) Same as 2a, but for E-E. White areas denote the time periods, where the array did not record. d) Reduced standing groundwater levels after normalization at ten wells near Harvey, where the black line is the mean curve. Their positions are shown in Figure 1. The green bar plot is the rainfall data; e) Sea level data (blue curve) and temperature data (magenta curve) at Bunbury. 

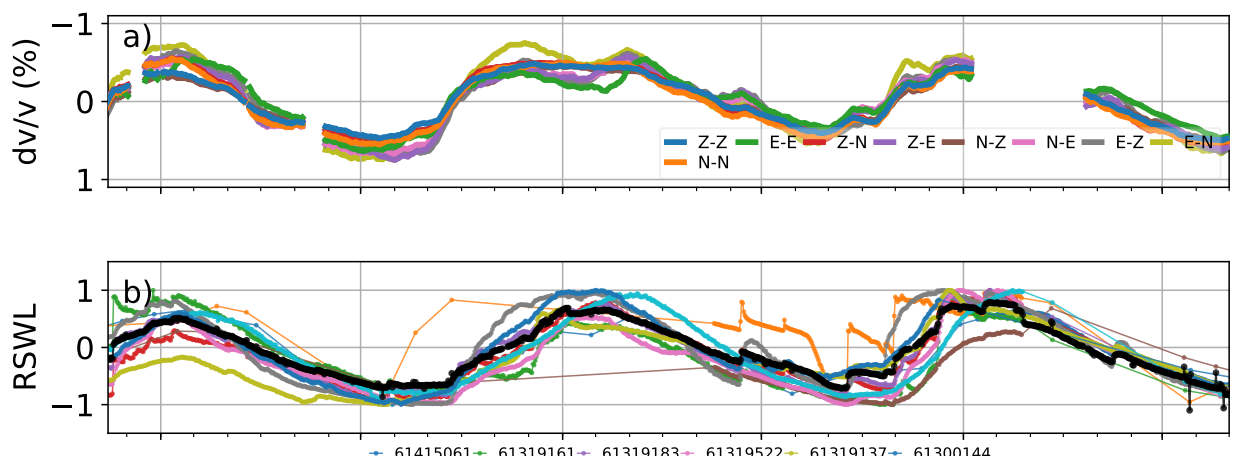

$61415061+61319161+61319183 \div 61319522-61319137 \div 61300144$
$-61330120 \div 61319164 \div 61330121+61410650 \div 61319179-\operatorname{mean}$
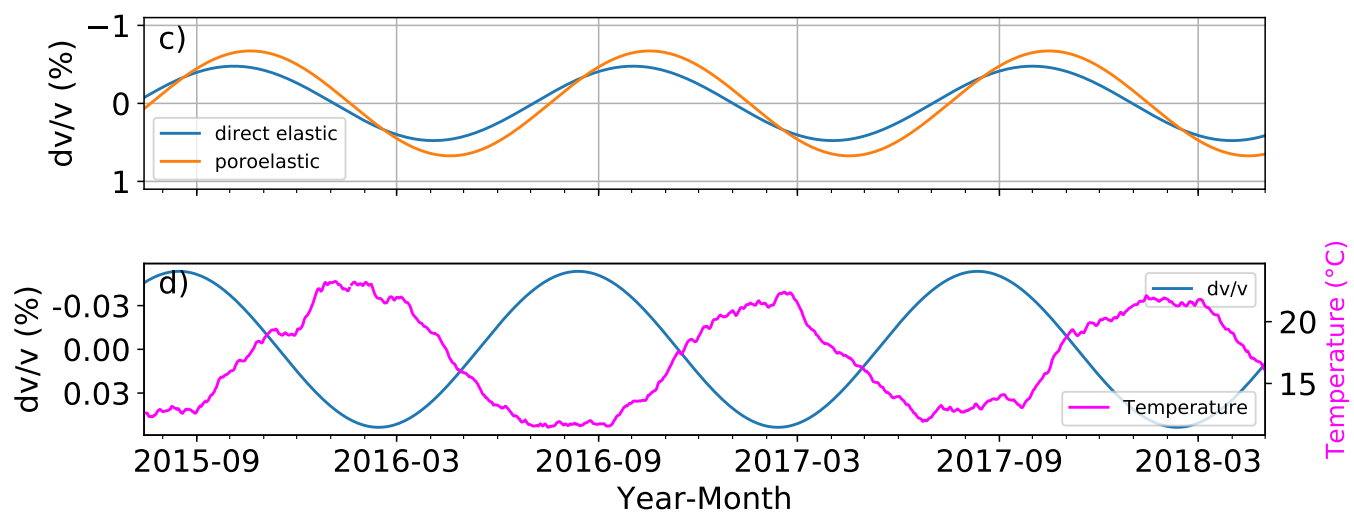

Figure 3. a) Relative velocity changes for different cross-correlation components (1-5 Hz). b) Reduced standing groundwater levels (RSWL) after normalization at ten wells near Harvey, where the black line is the mean curve. Their positions are shown in Figure 1. c) Modeled dv/v, the blue curve is for the direct elastic model, the orange curve is for the poroelastic model of Tsai (2011). d) Ambient air temperature changes (magenta) and the theoretical temperature induced $\mathrm{dv} / \mathrm{v}$ (blue). 